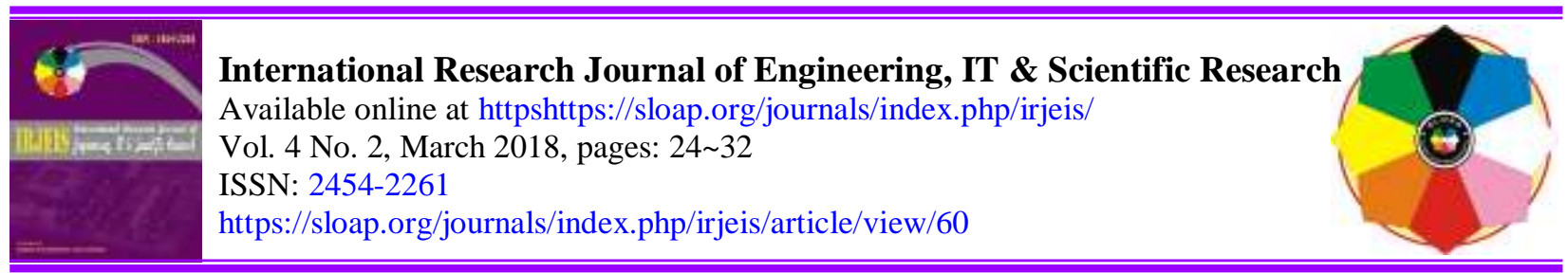

\title{
An Experimental Research with 3D Objects for the Internet of Things
}

Antonio Carlos Bento ${ }^{a}$

\section{Article history:}

Received: 15 July 2017

Revised: 21 January 2017

Approved: 10 February 2018

Published: 14 February 2018

\section{Keywords:}

IoT;

Display;

Nextion;

$3 D$ Builder;

Node MCU;

\begin{abstract}
This study presents the results of experimental research with the use of 3D resources. Unlike the creation and printing of physical objects, that can serve as an interface for 3D devices. The creation of solutions for the internet of things requires, besides the knowledge of programming, electronics, internet, and computing, also requires the creation of parts, which are often complex, for coupling and manipulation of devices to the internet of things. Personal experience during computer classes was the main motivation for the development of this work, demonstrating how to create solutions that can meet the different projects that involve the internet of things. In addition to presenting the results of a comparison between some tools evaluated during the research. The results were collected during the creation of the objects in 3D systems, besides presenting the results in pieces that were printed with this technology, these results demonstrated the possibility of creating viable solutions, and that can serve as a model for new projects, facilitating the development of solutions to the internet of things.
\end{abstract}

2454-2261 ${ }^{\circ}$ Copyright 2018. The Author. This is an open-access article under the CC BY-SA license (https://creativecommons.org/licenses/by-sa/4.0/) All rights reserved.

\section{Author correspondence:}

Antonio Carlos Bento,

Doctorate Program, Technologies of Intelligence and Digital Design,

Pontifícia Universidade Católica de São Paulo, Sâo PauloBrazil

Email address: acb01@Hotmail.com

\section{Introduction}

Due to the growth in the development of solutions for the internet of things. This project had the greatest motivation, the need to create objects that can serve as an interface for devices created for the internet of things, such as sensors, screens, couplings, among other needs involved during the projects to meet the transmission or receipt of data collected during the research. As a general objective, a discussion about the main tools existing between 2017 and 2018 should be presented. These tools are very used for the creation of 3D objects as if they were tools used by architects or engineers; these tools allow to define the size, colors, width, depth, as well as the connection for screws and openings for the passage of connecting devices.

${ }^{a}$ Pontifícia Universidade Católica de São Paulo, São Paulo, Brazil 
As a specific goal, a 3D project must be created to attend a particular study using the internet of things, the tools 3DBuilder, 123 Design, Google SketchUp should be analyzed. In this way, the reader will be able to understand its applications and implications in the creation of the solution after the creation of the project, the physical impression of the object must be performed to demonstrate its coupling with the Nextion and NodeMCU TFT devices. The results, although used in a specific project, could be adapted among other different types of projects, allowing them to be expanded to the different demands, as well as being the basis for future studies on the internet of things. This project besides being necessary a basic knowledge of computation also offers a cost considered low, because for the creation of the objects there are no costs, but for the printing, which can be done by renting or requesting an impression on demand.

As expected results, quantitative and qualitative data should be presented for the validation of the research, as well as the discussion about the different technologies used during the project. To exemplify the process, from the basic and basic needs for the construction of solutions for meet the type of project, allowing adaptation to more sophisticated projects which meet higher demands.

\section{Research Methods}

During the development of this project, the following research methods were used:

Basic research: to understand the main components involved, analyzing scientific materials, manuals among other commercial documents, about the products that can serve as a basis for the creation of the solution, mainly because it is modern technology. It is necessary a study on the literature that involves the universe about the products.

Experimental research: it should be presented other experiments that served as the basis for this project, enabling the creation of the solution. In this way were analyzed other projects that deal with the internet of things, in which specific solutions were presented for a certain real need, in this way validation of the studies through this experience. Presentation of current computational tools that are normally used for the creation of 3D objects should be presented some 3D printers, the type of material used for printing such as filaments. The development tools used in this study are: Microsoft 3DBuilder, AutodeskDesign 123Design, and Google SketchUp, these tools are known and easy to use, often used in different types of projects.

After the experiments are carried out, a real object must be developed, which must be tested and coupled to the project for the internet of things, this should use a NodeMCU 12e, which replaces an Arduino, it is greater capacity, speed, and data communication with WiFi networks. In addition to the use of a Nextion 2.5 "TFT touchscreen, which was used to configure the devices, besides presenting the data on the screen, serving as an interface between the user and the device.

The bibliographical references for the use of the methods and approach of the project were based on the works developed and presented by Marconi and Lakatos (2017). Being this a reference in the studies for the development of projects of academic research, demonstrating the structure of a project, its phases, and forms of organization and structure, as well as the main topics that involve scientific research. Repetier software was used to print objects; this program allows the conversion of files that were developed in the 3D tools like 3DBuilder to the print format in STL file. With Repetier it is possible to control the creation of the object. During the printing of layer levels as well as orientation and arrangement of the object in the 3D printer.

The bibliographic research was carried out on the internet subject of things presented by: Cui [5], Drucker [6], Li et. al. [8], Ma et. al. [9], Mukhopadhyay \& Suryadevara [11], Osemwegie et. al. [12], Stankovic [16], Whitmore and Agarwal [19], Wortmann \& Flüchter [20], Zanella [21]. On the NodeMCU 12e device, the following authors were studied: Bento [1][2][3][4], Kamel et. al. [7], Siva [13], Škraba et. al. [14], Škraba [15]. On the 3D printing features, involving 3D Builder software, the following works were studied: Micallef [11], Turbovich et al. [17], Wang et al. [18].

\section{Results and Analysis}

For the use of the materials, several devices for the construction of 3D objects were studied, the studies were developed in the Brazilian national market, which has imported equipment divided into pieces, which are usually assembled and sold as a complete product. The various types of equipment that are of international origin. After the study, we selected low cost, quality equipment that could satisfactorily meet the requirements. Based on these requirements, the Stella 3D printer was selected because it is easy to acquire, as well as low cost, as detailed in following.

Bento, A. C. (2018). An Experimental Research with 3D Objects for the Internet of Things. International Research Journal of Engineering, IT \& Scientific Research, 4(2), 24-32. https://sloap.org/journals/index.php/irjeis/article/view/60 


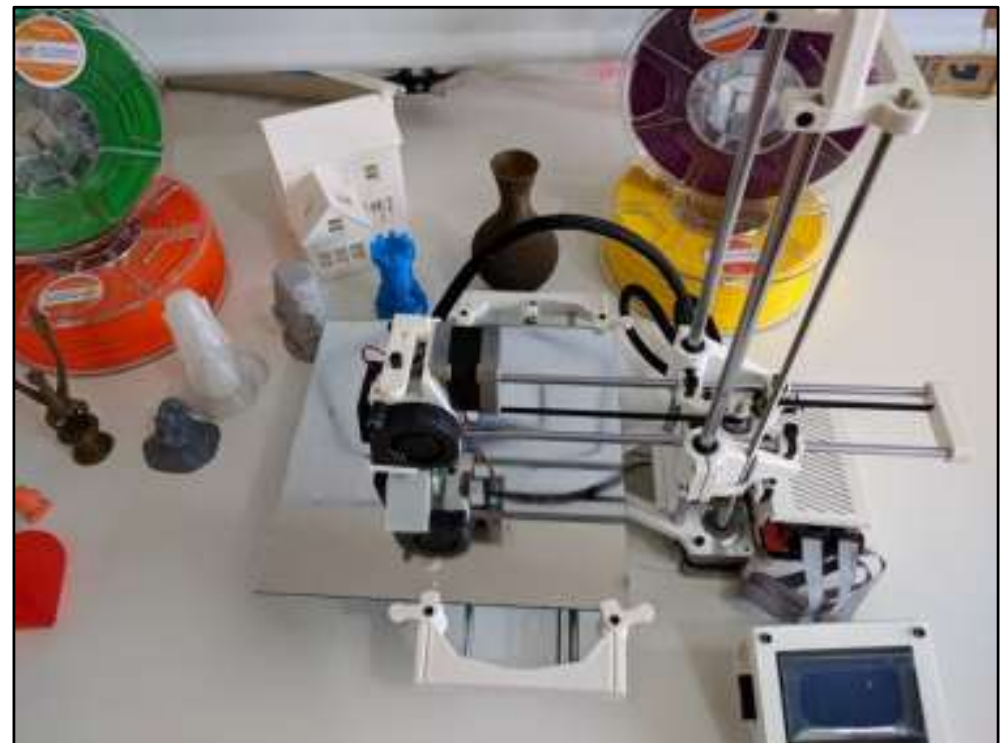

Figure 1. Stella $3 D$ printer, selected for the printing of objects.

The Stella printer was selected for its simplicity and low cost. The final cost of the device was around 900.00 dollars, is available in different colors, some specifications are selected during the purchase of the printer, such as the type of nozzle injector, as well as their heating capacity, these requirements serve to improve the quality of the parts.

To use the printer you need to set up the Repetier software which is free. It is used to configure the print quality as well as some specific characteristics of the Stella printer, such as speed, layers between the position of objects during printing.

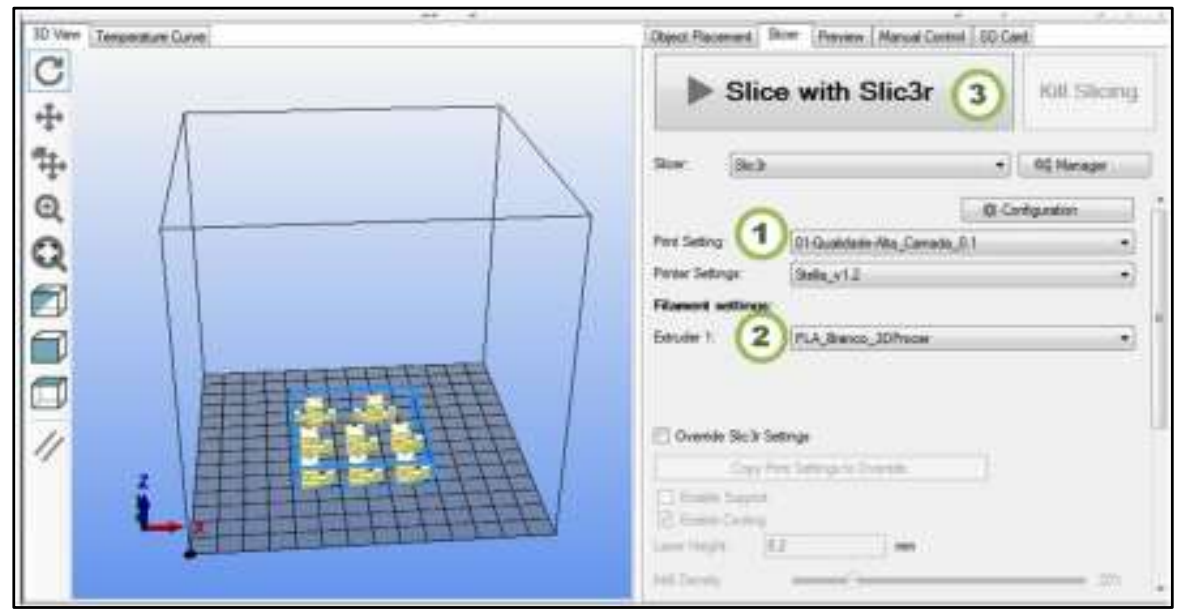

Figure 2. Slitting screen with Repetier software for printing on Stella 3D

When printing with Repetier software, it is necessary to configure the type of printer. The slicing off the part, i.e., the layers that should be required, considering the quality of the object, the layers may interfere with the final result, it is also configured the type of filament, in this case, the PLA was the material used, because it is less aggressive in the environment, it is not toxic to the human being, in case other material like the PET, are considered for objects like vases between other pieces in which it should not have direct contact with users.

Following the definition of the printer and the software for slicing, different systems were studied for the construction of 3D objects, such as Autodesk Design, Google SketchUp, and these are more complex resources, requiring a more in-depth technical knowledge. In this way, after analyzing Microsoft's 3D Builder software, 
which is already installed in the Windows 10 operating system, it was selected for its simplicity and objectivity in the construction of 3D objects.

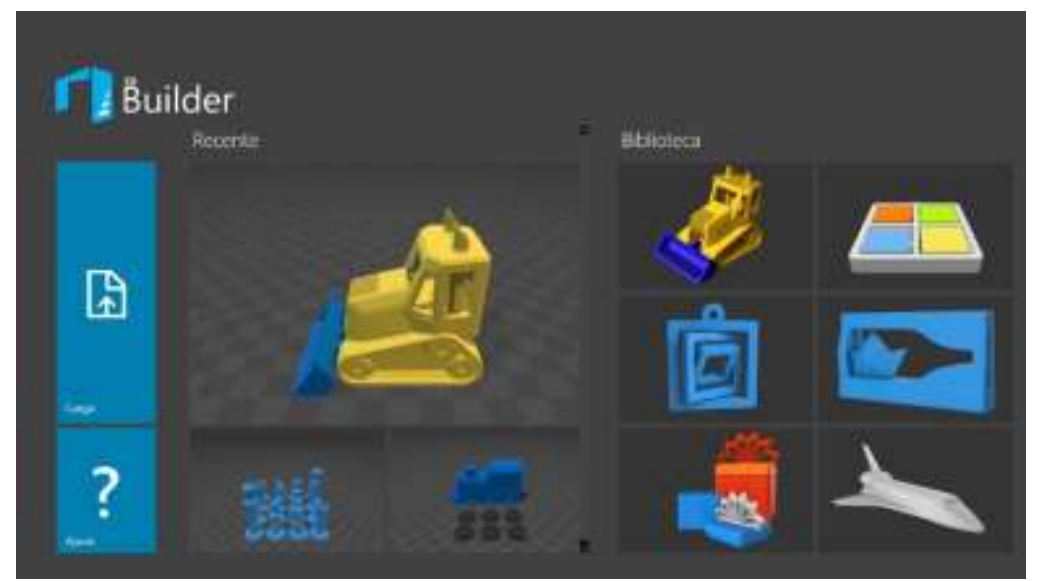

Figure 3. Microsoft 3D Builder Application Home Screen.

In the initial screen, it is possible to select some models for example of creation. Besides allowing the opening of previously developed projects. There are several templates to be used, the basic features of construction are the expansions, rotations, duplication, these basic features allow you to build a myriad of objects as well as your organization.

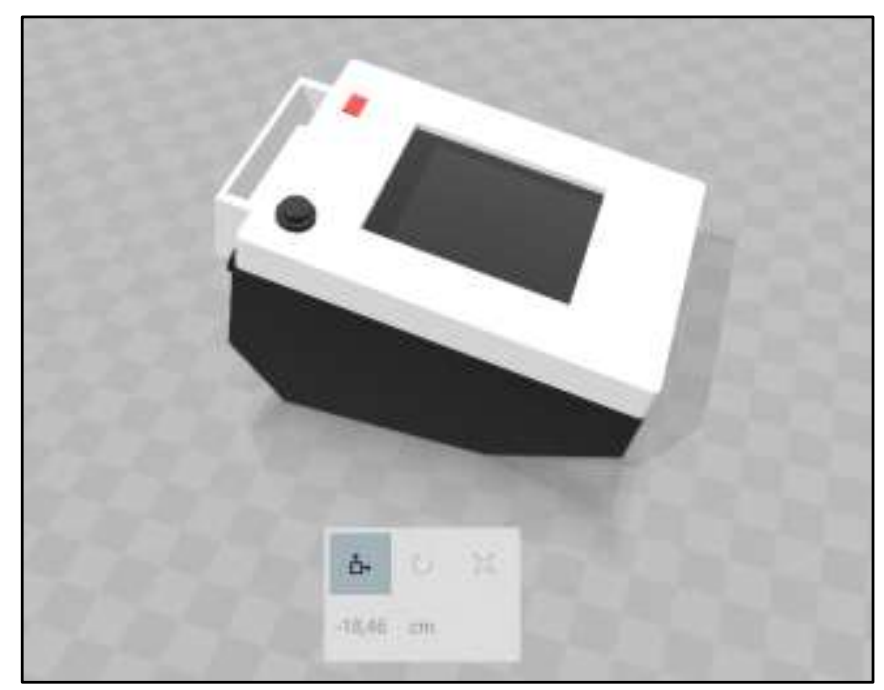

Figure 4. Final result of the $3 D$ object created in 3D Builder software

As a final result, we have the 3D object created in 3D Builder software, using the basic features of the tool, and the bottom part of the object was used the box model for electronic devices presented by the company Patola, model PB-204/3. With the Patola model, the bottom was removed, and the device was turned upside down, the top part being the support for the Nextion TFT display, serving as a lock and for control and configuration of the NodeMCU 12e device in conjunction with Shield for expansion of connections and resources.

Bento, A. C. (2018). An Experimental Research with 3D Objects for the Internet of Things. International Research Journal of Engineering, IT \& Scientific Research, 4(2), 24-32. https://sloap.org/journals/index.php/irjeis/article/view/60 


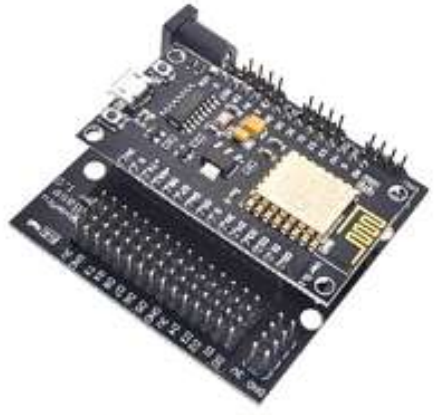

NodeMCU 12e + Shield V3

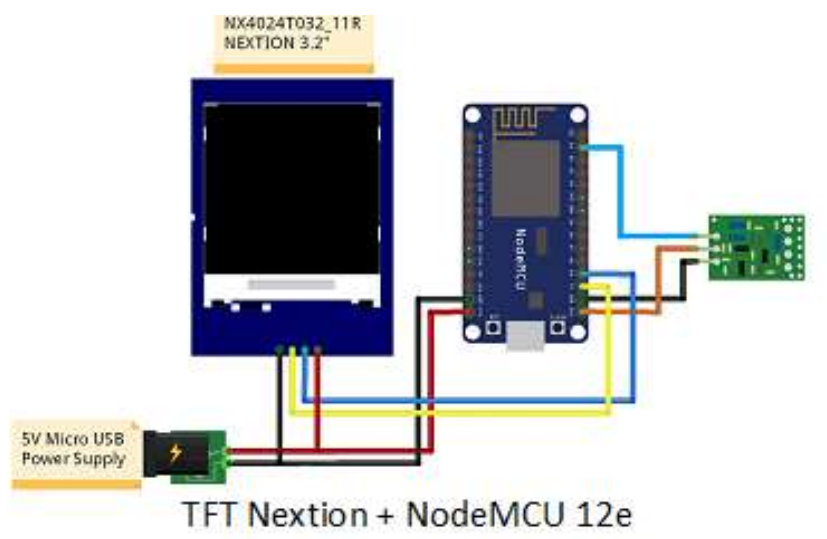

TFT Nextion + NodeMCU 12e

Figure 5 Nextion TFT connection scheme with NodeMCU 12e

The printed objects and their proper coupling must then be presented with the Nextion 2.5 "TFT devices and NodeMCU, already properly fixed and in operation.
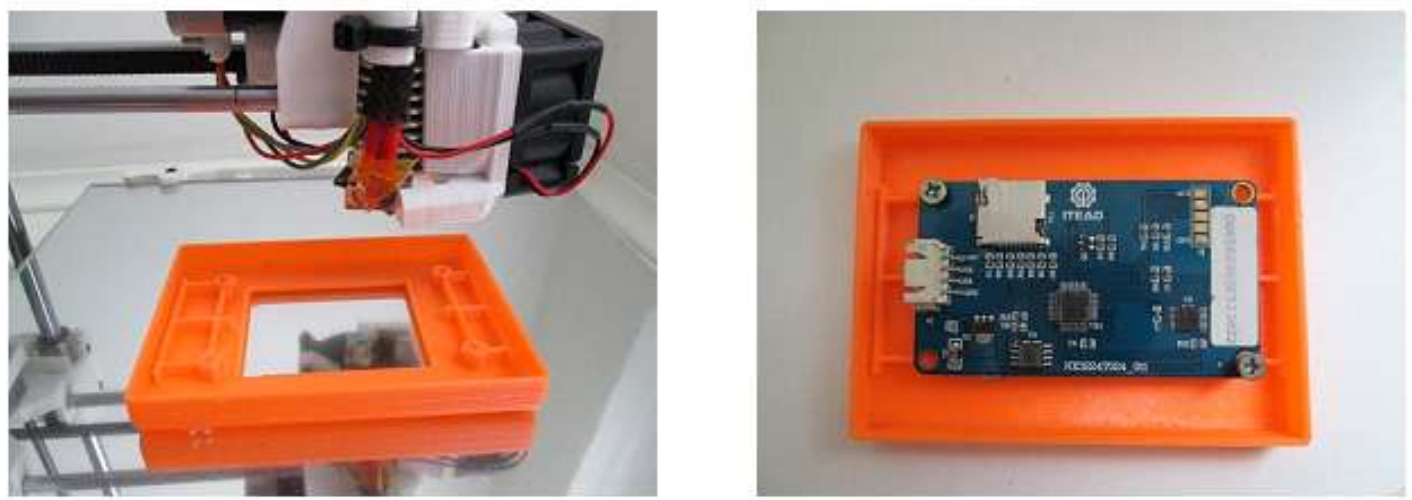

Figure 6 TF Nextion printing and coupling process

The printing process took about 1 hour; the 3D object was removed from the print tray, then the Nextion device fastened with screws on the 3D object, the construction of this object allowed the connection of the devices, as well as the realization specific tests to validate its operation. Despite being a simple model, the object meets the needs for coupling devices such as touch monitors, among other types that serve as the interface, for configuration, alteration, and presentation of data, collected during the use of sensors, or even for the presentation of images, and other features. 

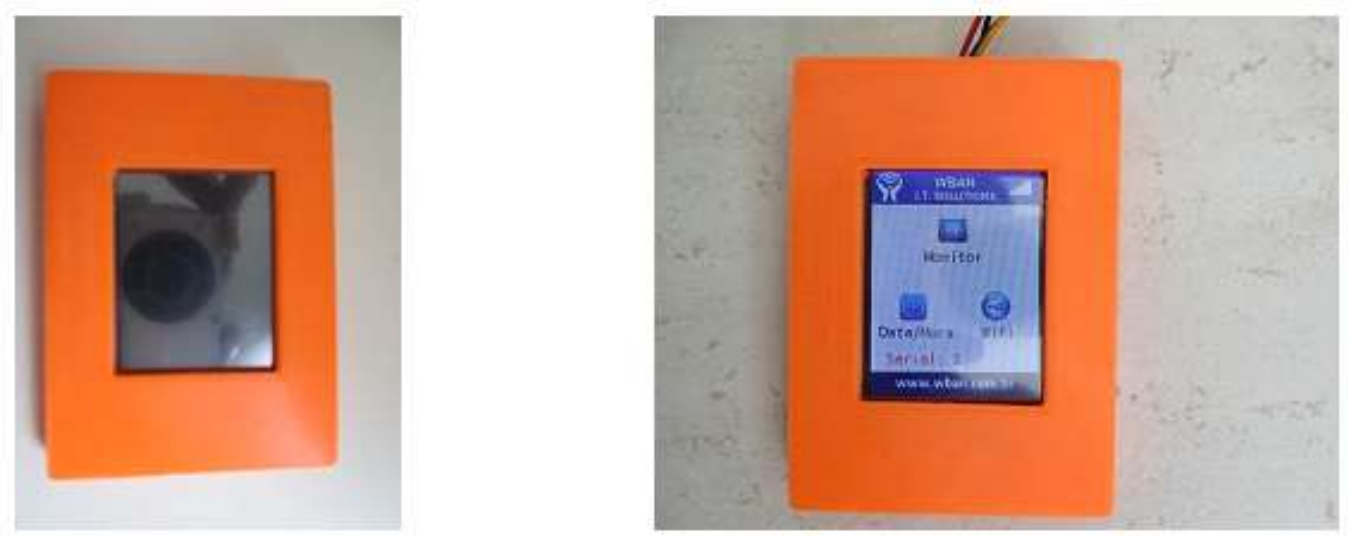

Figure 7 TF Nextion TFT device fixed to 3D object

With the object properly printed and the Nextion TFT device coupled, it was possible to carry out the connection and connection test on the electrical part, thus demonstrating the operation of the already fixed device and with the appropriate programming, codes loaded.
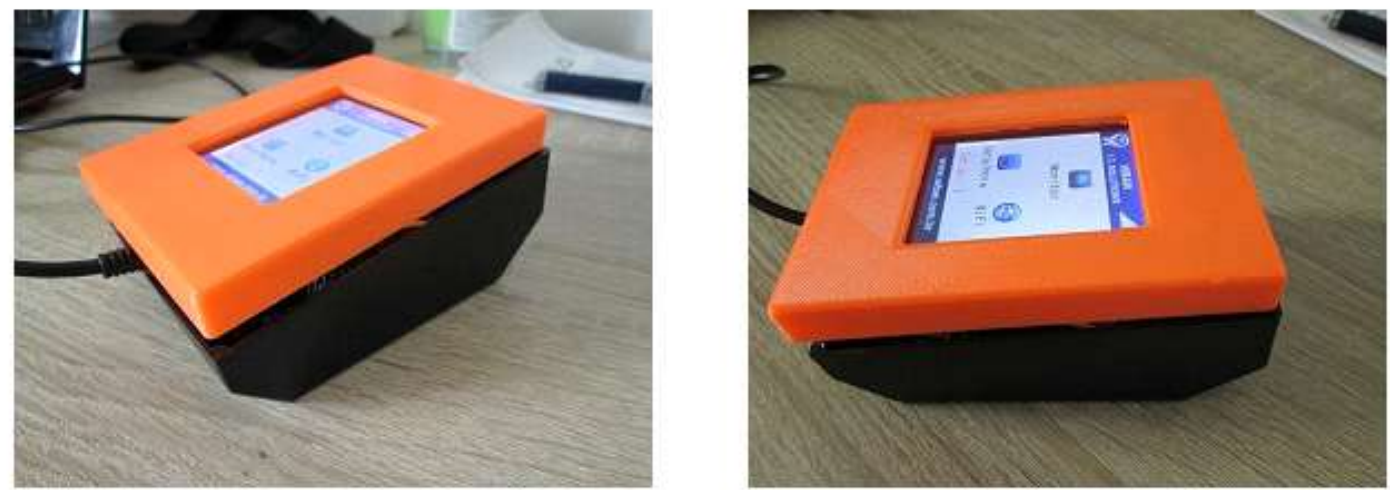

Figure 8 TF 3D object printed and coupled with the Nextion TFT, connected in the Patola PB-204/3 box

After all the tests with the coupled devices were carried out, the set was fixed in the Patola model PB-204/3 box. Also the power buttons were set, among other more specific features, to meet the different types of projects, considering small or large models.

Considering the results, it was possible to develop a model that can meet different types of projects, according to the type of Tex Nextion display of size of 2.5 inches. This type of display beside being the cheapest, meets different types of needs, using the basic features, such as allowing the configuration of sensors and recording and changing the date and time. These results allowed us to validate the use of the presented resources. Besides providing a model for more sophisticated projects, the creation of $3 \mathrm{D}$ objects, enabled prototyping and testing with the NodeMCU and Nextion devices, offering a broad view of how it could be coupling in different environments and configurations, to meet demands on various needs.

\section{Conclusion}

With the results of these studies, was to present in a practical way the use of 3D resources, to build solutions for the internet of things, serving as the basis for future projects, which can use this type of technology, due to the large number of tools available in the market, the focus of this study was to present a simple and feasible solution for project completion.

Bento, A. C. (2018). An Experimental Research with 3D Objects for the Internet of Things. International Research Journal of Engineering, IT \& Scientific Research, 4(2), 24-32. https://sloap.org/journals/index.php/irjeis/article/view/60 
Despite the high cost of 3D printers in the Brazilian market, it was possible to identify its efficiency in the construction of objects that can have a medium scale. In this way, the production can be realized to meet small market demand, besides demonstrating as a reality even more current, about the materialization of objects using $3 \mathrm{D}$ resources.

The low cost involved in this project also demonstrates the ability to serve a small project, which requires only one or a few devices, typically used during classes, or for demonstrating solutions to the internet of things. The internet of things is a reality that only grows the enthusiasm of its followers, by facilitating the automation and communication between different devices. The costs involved in the creation of 3D objects are none because different computer systems allow the user to use their creativity to create different solutions. It is necessary an early study understand the main features of this step, which are still very similar to each other, will allow the user to evolve in their projects.

The highest cost involved the purchase of the 3D printer, which involved the value of $\$ 600.00$, in addition to the filaments PLA, the material used to create the objects, which cost $\$ 60.00$. The time of creation of the pieces varied between 1 and 2 hours, is extremely fast, compared with the complexity of the structure of each object constructed, the results demonstrated quality. It was hoped that the results of this study could contribute to the development and application in larger projects. Its complexity could contribute to the creation of new solutions that could serve the projects for the internet of things, among other types of projects used for demonstration, or even for a production, capable of solving some of the problems of society.

\section{Acknowledgements}

The author would like thanking an editor in IRJEIS for their valuable time and advice. 


\section{References}

1. Bento A. C. (2018). IoT: NodeMCU 12e X Arduino Uno, Results of an experimental and comparative survey. International Journal of Advance Research in Computer Science and Management Studies, v. 6, p. 46-56, 2018.

2. Bento, A. C. (2018). IoT: Results of an Experimental Survey with Nodemcu, Nextion, DS1307 and NRF24L01+. International Journal of Current Innovation Research, v. 4, p. 969-974-974, 2018.

3. Bento, A. C. (2018). IoT: Results of an experimental survey with NodeMCU 12e, TFT Nextion and RTC DS1307. International Journal of Advance Research in Engineering, Science \& Technology, v. 5, p. 6-14, 2018.

4. Bento, A. (2018). Internet of Things: An Experiment with Residential Automation for Robotics Classes. International Research Journal Of Management, IT \& Social Sciences, 5(2), 113-119. doi:10.21744/irjmis.v5i2.623

5. Cui, X. (2016). The internet of things. In Ethical Ripples of Creativity and Innovation (pp. 61-68). Palgrave Macmillan, London.

6. Drucker, P. F. (2015). Internet of things - position paper on standardization for IoT technologies. European Research Cluster on Internet of Things, 1-142.

7. Kamal, M. M., Noar, N. A. Z. M., \& Sabri, A. M. (2018). Development of Detection and Flood Monitoring via Blynk Apps. Indonesian Journal of Electrical Engineering and Computer Science, 10(1).

8. Li, S., Da Xu, L., \& Zhao, S. (2015). The internet of things: a survey. Information Systems Frontiers, 17(2), 243259.

9. Ma, J., Zhou, X., Li, S., \& Li, Z. (2011, October). Connecting agriculture to the internet of things through sensor networks. In Internet of Things (iThings/CPSCom), 2011 International Conference on and 4th International Conference on Cyber, Physical and Social Computing (pp. 184-187). IEEE.

10. Micallef, J. (2015). Exploring Design Techniques for 3D Printing. In Beginning Design for 3D Printing (pp. 3166). Apress, Berkeley, CA.

11. Mukhopadhyay, S. C., \& Suryadevara, N. K. (2014). Internet of things: Challenges and opportunities. In Internet of Things (pp. 1-17). Springer, Cham.

12. Osemwegie, O., John, S., Okokpujie, K., \& Shorinwa, I. (2016, December). Development Of An Electronic Fare Collection System Using Stationary Tap-Out Devices. In Computational Science and Computational Intelligence (CSCI), 2016 International Conference on (pp. 234-236). IEEE.

13. Reddy, P. S. N., Vardhan, D. V., Reddy, K. T. K., \& Reddy, P. A. K. (2018). An IoT-Based Low-Cost Weather Monitoring and Alert System Using Node MCU. In Smart Computing and Informatics (pp. 265-274). Springer, Singapore.

14. Škraba, A., Koložvari, A., Kofjač, D., Stojanović, R., Stanovov, V., \& Semenkin, E. (2017, June). Prototype of group heart rate monitoring with NODEMCU ESP8266. In Embedded Computing (MECO), 2017 6th Mediterranean Conference on(pp. 1-4). IEEE.

15. Škraba, A., Koložvari, A., Kofjač, D., Stojanović, R., Stanovov, V., \& Semenkin, E. (2016, June). Streaming pulse data to the cloud with bluetooth LE or NODEMCU ESP8266. In Embedded Computing (MECO), 2016 5th Mediterranean Conference on (pp. 428-431). IEEE.

16. Stenbrunn, A., \& Lindquist, T. (2015). Hosting a building management system on a smart network camera: On the development of an IoT system.

17. Turbovich, Z. N., Avital, I., Mazor, G., Das, A. K., \& Kalita, P. C. (2017, January). Personal 3D Printer: Selfdesign and Manufacturing. In International Conference on Research into Design (pp. 327-338). Springer, Singapore.

18. Wang, J., Qian, W., \& Liu, H. (2017, July). Shape Analysis of Pottery Using Elliptic Fourier Descriptor and 3D Scanning. In International Conference on Applied Human Factors and Ergonomics (pp. 62-70). Springer, Cham.

19. Whitmore, A., Agarwal, A., \& Da Xu, L. (2015). The Internet of Things-A survey of topics and trends. Information Systems Frontiers, 17(2), 261-274.

20. Wortmann, F. \& Flüchter, K. Bus Inf Syst Eng. (2015) 57: 221. Internet of Things Technology and Value Added. Springer Fachmedien Wiesbaden. Online ISSN 1867-0202. DOI: https://doi.org/10.1007/s12599-015-0383-3.

21.Zanella, A., Bui, N., Castellani, A., Vangelista, L., \& Zorzi, M. (2014). Internet of things for smart cities. IEEE Internet of Things journal, 1(1), 22-32.

22. Delgado, G. R. E., Meza, A. K. T., Chávez, S. A. R., \& Murillo, G. S. A. (2018). Demands of People with Disabilities and Empowerment of Resilient Strategies. International Research Journal of Management, IT and Social Sciences (IRJMIS), 5(1), 45-54.

Bento, A. C. (2018). An Experimental Research with 3D Objects for the Internet of Things. International Research Journal of Engineering, IT \& Scientific Research, 4(2), 24-32. https://sloap.org/journals/index.php/irjeis/article/view/60 
23. Delgado, G. R. E., Meza, A. K. T., \& García, A. E. G. (2018). Resilient Factors in Students with Disabilities. International Research Journal of Management, IT and Social Sciences (IRJMIS), 5(2), $23-31$.

24. Hadi, A., Handajani, L., \& Putra, I. N. N. A. (2018). Financial Disclosure based on Web-ICT Determinants: Its Implications for Local Government Financial Performance in Indonesia. International Research Journal of Management, IT and Social Sciences (IRJMIS), 5(1), 72-85.

25. Ghosh, C. (2017). A Study on-Evaluating Marketing Strategies Adopted by Home Appliance for Economic Development in India. International Journal of Social Sciences and Humanities (IJSSH), 1(1), 9-15.

26. Jain, P. (2017). Effect of Online Education Trend on Quality Management. International Journal of Health Sciences (IJHS), 1(1), 1-5.

27. Arauz, W. M. S., Cedeño, G. I., Chávez, S. S., Pérez, A. V., \& Gámez, M. R. (2017). Microgrid With a 3.4 kWp Photovoltaic System in the Universidad Técnica de Manabí. International Journal of Physical Sciences and Engineering (IJPSE), 1(2), 11-20.

28. Jaminyasa, I. M., Pulawan, I. M., \& Amerta, I. M. S. (2017). The Marketing Mix Affect on the Consumer Buying Decision (Case Study of Sausage Products at PT. Aroma Denpasar). International Journal of Social Sciences and Humanities (IJSSH), 1(2), 65-74.

29. Widana, I. W., Parwata, I. M. Y., Parmithi, N. N., Jayantika, I. G. A. T., Sukendra, K., \& Sumandya, I. W. (2018). Higher Order Thinking Skills Assessment towards Critical Thinking on Mathematics Lesson. International Journal of Social Sciences and Humanities (IJSSH), 2(1), 24-32.

\section{Biography of Author}

\begin{tabular}{||l|l|}
\hline \hline 5 & $\begin{array}{l}\text { Doctor in Cognitive Environments and Digital Design in the course of Technologies of } \\
\text { Intelligence and Digital Design of PUC-SP. He holds a Master's degree in Information } \\
\text { Systems Technology from the Fundação and Instituto de Ensino Para Osasco. He holds } \\
\text { an MBA in Information Systems from the University of São Paulo. He graduated in } \\
\text { Data Processing from Ibirapuera University and is currently a professor in } \\
\text { undergraduate and postgraduate courses. He has experience in the area of Computer } \\
\text { Science, with emphasis on Information Technology, Project Management, Database, } \\
\text { Software Engineering, Software Systems for Education, Intelligent Systems and } \\
\text { Specialists, Security, Systems Modeling and Information Technology Management. } \\
\text { Acting on WBAN projects, artificial intelligence, and information technology. }\end{array}$ \\
\hline
\end{tabular}

